\title{
LA HISTORIA DE LA HISTORIOGRAFÍA LITERARIA ESPAÑOLA. LA HISTORIA LITERARIA DE GERARDO DIEGO
}

\author{
Antonio Martín Ezpeleta \\ Universidad de Zaragoza
}

Dentro de la reflexión sobre el pensamiento literario español del siglo $\mathrm{XX}$, el estudio de las Historias literarias españolas ocupa un lugar muy relevante. De ahí que propongamos a continuación una reflexión sobre la importancia de la disciplina de la Historiografía literaria cspañola e insistamos en la necesidad de activar la redacción de una Historia de la historiografía literaria española. En este caso, nuestra modesta contribución a esta deseable obra nos lleva a contextualizar y caracterizar brevemente la poco conocida Historia literaria de Gerardo Diego'.

\section{La disciplina de la Historiograf̆a literaria y la Historia de la historiografía literaria.}

La pujante disciplina de la Historiografía literaria, ubicada dentro de la Historia de la crítica literaria, persigue el análisis de las Historias literarias, las antologías y todos aquellos estudios relevantes que, superando los planteamientos muy particulares y sincrónicos, han colaborado en la conformación de la idea de una Historia de la literatura nacional, así como del canon de autores que esta comporta. Sorprende cómo una línea de trabajo que compagina la recuperación de los aciertos de muchos críticos literarios del pasado, la escritura de una propedéutica y necesaria Historia de la historiografía literaria, es decir, la Historia de las Historias literarias escritas, y, en fin, la revisión última de uno de los caminos más transitados de la Historia de la crítica literaria, la Historia de la literatura nacional, haya sido irremediablemente aplazada para el caso español,

1.- Esta es la línea de trabajo que seguimos. Concretamente, nos hemos preocupado en nuestra tesis doctoral, dirigida por el profesor Leonardo Romero Tobar, quien encabeza un grupo de investigación sobre Historiografía literaria española subvencionado por el Ministerio de Educación y Ciencia (HUM2005-06063/FILO). En "La Historiografía literaria española hoy. Notas sobre los manuales de literatura de Giménez Caballero" [Martín Ezpeleta, en prensa], puede encontrarse un pequeño estado de la cuestión sobre esta disciplina de la Historiografía literaria, así como en la mencionada tesis doctoral inédita, de donde procede una parte de este trabajo. 


\section{LA HISTORIA DE LA HISTORIOGRAFÍA LITERARIA ESPAÑOLA}

en flagrante contradicción con el caso de otras literaturas nacionales como, paradigmáticamente, la alemana ${ }^{2}$.

Dicha disciplina de la Historiografía literaria, como se deducirá, presenta la peculiaridad de interesar de manera semejante a historiadores y teóricos de la literatura. Si hablamos de la recuperación de los críticos del pasado, la ordenación y plasmación de este material en una Historia de la historiografía literaria, estamos refiriéndonos a tareas que incumben sobremanera a los historiadores. Pero si, por otro lado, pensamos en el estudio de las diferentes corrientes literarias (formalismo, comparatismo...), las metodologías a la hora de escribir una Historia literaria (periodización de la Historia de la literatura, conceptos como el de generación literaria...) y todo el debate que encierra la idea de canon, nos damos cuenta de que se trata de cuestiones que han recibido un creciente interés en los últimos años por parte de los teóricos de la literatura ${ }^{3}$.

Conviene que expliquemos que se suele denominar Historiografía literaria al quehacer de la Historia de la historiografía literaria o, también utilizado, Historia de las Historias literarias, como ya hemos visto, es decir, la disposición crítica de las Historias literarias nacionales en el decurso de la historia socio-política y filológica. Para algunos, esta es la principal tarea de la Historiografía literaria, aunque hay que señalar que existe otra opción que of rece gran rendimiento crítico: el estudio transversal de un motivo concreto a lo largo de varias Historias literarias. Es el caso de la configuración de determinados conceptos y términos historiográficoliterarios, como el de una generación literaria o un movimiento como el Romanticismo, el Modernismo..., además de motivos tan interesantes como es la señalada división periodológica de la Historia de la literatura, por ejemplo, y, por supuesto, el estudio de la repercusión de un autor o todas aquellas cuestiones relacionadas con la conformación del canon nacional, aspecto este comentado que, junto con el valor didáctico, emparenta definitivamente las Historias literarias con las antologías.

Por otro lado, debemos considerar, como ya hemos subrayado en otra ocasión [cfr. Martín Ezpeleta, en prensa], que la Historiografía literaria no es sólo una construcción de la Historia de la crítica literaria que, sorprendentemente, ha pasado muchas veces por alto las Historias literarias; sino también una manera de rescatar planteamientos válidos y novedosos, que pueden ser aprovechados por los historiógrafos literarios contemporáneos, en ese proceso retroalimenticio que supone, en último término, la Historia de la crítica literaria en general. Además, las Historias literarias contienen testimonios muy útiles para la reconstrucción

2.- Para el caso español, contamos singularmente con la monografía sin traducción de Baasner [1995], que detiene su análisis de Historias literarias españolas en 1868. Otros trabajos muy meritorios en la misma línea son los de Álvarez Barrientos y Mestre [1995], Carballo Picazo [1967], Cebrián [1996], Fernández-Cifuentes [2004], Garrido Palazón [1994], Martín Ezpeleta [<www.liceus.com>], Meregalli [1990], Romero Tobar [1999, 2003], Rubio Jiménez [2004] o Urzainqui [1987], entre otros, que, en cierta medida, preparan el camino para esta tantas veces demandada Historia de la historiografía literaria española (faltaría, eso sí, incluir un buen número de Historias literarias olvidadas e insistir en el análisis de muchas de ellas, pues son numerosas las que tan sólo han sido mínimamente contextualizadas). Algo más de atención han recibido los manuales de literatura de secundaria, vid. Fernando Valls [1983] o Gabriel Núñez y Mar Campos [2005], por ejemplo.

3.- Tal y como se ilustra en las recientes obras colectivas Rethinking Literary History. A Dialogue on Theory [Hutcheon y Valdés San Martín (eds.), 2002], Historia literaria/Historia de la literatura [Romero Tobar (ed.), 2004] o Teorías de la historia literaria [Beltrán y Escrig (eds.), 2004], por ejemplo. Sobre estas cuestiones, vid. también los pioneros trabajos de Claudio Guillén [1971, 1989].

4.- Vid., sobre la relación que se establece entre las Historias literarias y las antologías, Romero Tobar [1998: 50-53] y Mainer [1998: 272-275, 293 y 298-299]. Sobre el canon, algunas referencias fundamentales son los estudios de Pozuelo Yvancos [1996; (coord.), 1996]; Pozuelo Yvancos y Aradra Sánchez [2000]; y la compilación de trabajos de Sullà [Harold Bloom et al., 1998]. 


\section{ANTONIO MARTÍN EZPELETA}

historicista. La idea del Volksgeist español, la voz de los escritores exiliados, etcétera, son testimonios que nos hacen pensar en la necesidad de contextualizar las Historias literarias, como si se tratara de novelas o poemarios, como hijas de una época y un autor subjetivo (cuando se trata de uno sólo) $)^{5}$.

Yesque, lejos de ser un narrador objetivo, el autor está condicionando su obra, individualizándola y dotándola de un sesgo propio, necesario para que su Historia literaria tenga más valor que el de mero catálogo de autores y obras, centón de datos que exigen un criterio subjetivo para conformar un canon, explicar el cambio histórico, el genio nacional para unos, la expresión artística por medio de la literatura, etcétera. En este sentido, lo subjetivo y original-que no interfieren con el rigor científico-, siempre ha de ser estudiado, valorando después su importancia, que el transcurso de la historia de la crítica muchas veces nos aclara. Pensemos que la función más importante del historiador es la de seleccionar, donde indefectiblemente encontramos este subjetivismo del que venimos hablando [ibíd.].

En fin, no debemos olvidar que las Historias literarias son obras destinadas a un público mixto de especialistas y estudiantes, por lo que su tono ha de ser lo suficientemente riguroso y técnico, pero con una clara vocación expositiva y divulgativa. Los planteamientos excesivamente originales suelen ser, por esta razón, atenuados, al igual que el discurso, que se decanta por un estilo claro y preciso, aunque pucda afectarse, lógicamente, en ocasiones. Las aportaciones no suelen ser en cuestiones concretas, y si lo son, se subordinan por norma general, en nota al pie, por ejemplo. El talento del autor se plasma realmente en los esquemas organizativos teóricometodológicos, y el grado de madurez del conocimiento de la literatura y las diversas disciplinas humanísticas que confluyen en una Historia literaria (Historia, Filosofía, Arte...). Por ello, tras la descripción analítica de una Historia literaria, la misión última de un estudioso de Historias literarias es, en este sentido, señalar estos aspectos y valorar su aportación a la comprensión de la idea de la Historia de la literatura nacional en cuestión. Esto es lo que procuramos llevar a cabo ahora en el caso concreto de la Historia literaria de Gerardo Diego.

\section{La Historia literaria de Gerardo Diego}

Brevemente, señalemos que el repaso la trayectoria de la Historiografía literaria española en la primera mitad del siglo XX revela la publicación de un número elevado de Historias

5.- La estrecha relación que se establece entre los historiadores y los escritores de creación ha sido subrayada en más de una ocasión. Además de los estudios narratológicos de Hayden White [1992...], nos referimos a reflexiones como esta de Menéndez Pelayo, que ha sintetizado Laín Entralgo en su estudio Menéndez Pelayo. Historia de sus problemas intelectuales: «Ni el poeta puede hacer poesía desligándose del mundo real -natural e histórico-, ni el historiador escribirá historia propiamente dicha si sólo se atiene a lo visible con los ojos de la cara. De aquí el tránsito continuo entre la historia o la poesía histórica. [...]. El poeta y el historiador se asemejan, pues, negativa y positivamente. Negativamente, en cuanto no pueden desligarse de la realidad natural e histórica. Positivamente, en cuanto uno y otro cumplen su oficio leyendo lo que de universalmente humano hay en el fondo de sus personajes. El pocta puede hacerlo plenamente y sin trabas, porque - en el momento inicial de la concepción poética, al menos-es "dueño de sus personajes, históricos o inventados, puede penetrar hasta en los senos de su conciencia, poner en clara luz los recónditos motivos de sus acciones...". El historiador, en cambio, sólo puede proceder "por indicios, conjeturas y probabilidades". La comprensión histórica tiene, pues, un fundamental carácter poético» [1944: 302303]. Sobre la deconstrucción de la oposición historiador-escritor de creación, vid. el trabajo de Túa Blesa [2004], que recoge otros interesantes testimonios, así como sucede en la introducción de Domingo Ródenas a la edición de la Obra crítica de Benjamín Jarnés [2001], donde recopila relevantes ejemplos nacionales y extranjeros de una tradición que identifica la crítica literaria con la creación. 


\section{LA HISTORIA DE LA HISTORIOGRAFÍA LITERARIA ESPAÑOLA}

literarias, un auténtico boom editorial ${ }^{6}$. Circularon muchas, aunque pocas se sustrajeron a la idea nacionalista del Volksgeist español. Su uso -y abuso- en ámbitos educativos las vino a convertir en casi referentes físicos de la idea de la Historia de la literatura española y del canon de autores y obras españoles. Desde el Romanticismo y con el espíritu del noventayocho de fondo, se consiguió excitar ese sentimiento nacionalista que tomó cuerpo en la idea del espíritu de los pueblos, que, como decimos, gobernaba la gran mayoría de Historias literarias de la época, y que tanto las desviaba hacia una suerte de "biografías nacionales"7. Este fenómeno, que ni mucho menos disonaba con la explosión poligenética de nacionalismos extremados que padecía Europa, termina de apuntalar esta contextualización de la Historia literaria de Gerardo Dicgo.

La Historia literaria de Gerardo Diego es, en puridad, un capítulo de la Historia de la literatura universal, dirigida por Ciriaco Pérez Bustamante, y que fue publicada por la madrileña editorial Atlas en 1946. Esta Historia de la literatura universal no era sino un enciclopedista compendio de introducciones a las Historias literarias nacionales de Egipto, India, China, Inglaterra, Alemania, Holanda, Portugal, Hispanoamérica, Rusia, Turquía... La redacción de cada capítulo correspondía a especialistas en la materia (Celada, Cantera, Van Horne, Gómes Branco...) que en pocas páginas debían despachar toda una Historia literaria nacional. En el prólogo se advierte cómo en realidad tan sólo se está preparando el primer paso de una Historia literaria universal a partir, paradójicamente, de la validación del concepto nacional:

Antes de acceder a una historia literaria universal, presidida por un criterio de riguroso sincronismo, es necesario formular una historia nacional de cada literatura. Entre su entidad individual y la totalidad [del] género humamo, el hombre encuentra una personalidad supraindividual, colectiva, de honda raigambre: la nacionalidad. Existen núcleos humanos homogéneos por razones de cultura y de raza, vinculados a un paisaje materno, y unidos en el común destino de realizaciones e ideales. En otros términos: existen unidades de pueblo y territorio, entidades intermedias entre humanidad e individuo. Son la naciones.

La nación es sujeto de una historia política, previa a la historia política universal. También de una historia artística o literaria. Y al intentar entender, en toda su amplitud, la historia de la literatura, hallamos -lógicamente- literaturas nacionales, como dato previo a la Weltliteratur.

Este libro, por razones didácticas, se orienta hacia la historia de las literaturas nacionales. [...]

6.- Para esta cuestión, resulta fundamental el trabajo de Fermín de los Reyes aún inédito La Historia literaria española. Repertorio bibliográfico (1754-1936). (Agradecemos al profesor Fermín de los Reyes, compañero del equipo de investigación sobre Historiografía literaria dirigido por I.eonardo Romero Tobar, que nos haya brindado la posibilidad de consultar este trabajo antes de su publicación). Por otro lado, siguen siendo útiles los trabajos de Serís [1948], Simón Díaz [1983] y, para las Historias literarias publicadas en los Estados Unidos, Román [1975]. Vid. también Juana de José Prades, La Teoría Literaria (Retóricas, Poéticas, Preceptivas, etc.) [1954: 43-51] y cfr. Palau [1953, IV: 603-623]. Sobre la amplia producción de Historias literarias en Italia y España, ha escrito recientemente Ceserani lo siguiente: «En pocos países existe una producción tan extensa sobre historia de la literatura como cn Italia, y casi tanto podría decirse de España. Las hay de todo tipo: obras grandes y lujosas, escritas por equipos de especialistas y dirigidas por estudiosos de prestigio; obras más ligeras y divulgativas, distribuidas tal vez por entregas en los quioscos; manuales escolares; serias historias eruditas y manuales "confidenciales" para el gran público" [2004: 187]. El ensayo en los siglos XIX y XX de Aullón de Haro es útil para un acercamiento a las escuelas filológicas y la relación de las obras de crítica literaria más importantes [1984: 63-92 especialmente; cfr. Aullón de Haro, 1987: 27-30, 42-47, 83-86]. Sobre la Filología española de la primera mitad del siglo XX en general, es fundamental la obra de José Portolés, que atiende a la asimilación progresiva de las corrientes crítico-literarias europeas del positivismo e idealismo [Medio siglo de Filología española (1896-1952), 1986].

7.- Una aproximación a este momento de la Historiografía literaria española, puede encontrarse en Martín Expeleta, "La Historiografía literaria española de la primera mitad del siglo XX" [<www.liceus.com $>]$, trabajo que, de ningún modo, exime de la lectura de los de Mainer [1981, 1994], Romero Tobar [1998, 1999] y Pozuelo Yvancos [2000]. En la citada obra Historia literaria/Historia de la literatura, se incluye un apartado bibliográfico donde el lector interesado podrá recuperar numerosas referencias bibliográficas más [Romero Tobar (ed.), 2004: 421-457]. 


\title{
ANTONIO MARTÍN EZPELETA
}

\begin{abstract}
La historia sincrónica y unitaria queda, por tanto, fuera de nuestro propósito, esencialmente didáctico. Queda como un tema subalterno a la morfología de la cultura, para cuya comprensión es etapa previa e imprescindible un tratado como el que hoy ofrecemos a nuestros lectores. En la seguridad de que la lectura de este libro ofrece por sí misma a todo lector inteligente, la espontánea deducción de una síntesis hacia las más vastas perspectivas universales [1946: xIV-xv].
\end{abstract}

Así, Gerardo Diego (Santander, 1896 - Madrid, 1987), catedrático del Instituto Galindo de Madrid por aquel entonces, fue el encargado de redactar el capítulo más amplio de la obra, dedicado, como no podía ser de otra manera, a la Historia de la literatura española (además, también preparó el dedicado a la Historia de la literatura francesa). El mayor mérito de esta Historia literaria española está en haber sabido resumir en apenas setenta páginas divulgativas y amenas el canon de autores y obras tradicional que va desde el Cid hasta Ortega y D'Ors, con el inestimable auxilio bibliográfico de los estudios de Menéndez Pelayo y Menéndez. Pidal, y las Historias literarias de Cejador y Frauca, Merimée, Hurtado y González Palencia, Valbuena, Alonso Cortés, Díaz-Plaja, J. M. Blecua, Pfandl y Boselli-Vian, que cita convenientemente al final de la obra.

Encontramos, pues, una síntesis de los trabajos historiográfico-literarios más importantes del momento. Merece la pena que la desglosemos brevemente. Si Menéndez Pelayo, conciudadano de Gerardo Diego y muy admirado por este (le dedicó un opúsculo encomiástico de poco calado titulado Menéndez Pelayo en la Historia literaria [1956]) cra la gran autoridad $y$, en muchas ocasiones, la única, en cuestiones de literatura medieval Menéndez Pidal aventajaba a su maestro. Ni maestro ni discípulo llegaron a escribir una Historia literaria como tal, aunque otros compañeros de generación de Menéndez Pidal, Juan Hurtado y Ángel González Palencia, cuyos estudios humanísticos se distanciaron de la literatura española, sí. La Historia literaria de Hurtado y González Palencia, publicada por primera vez en 1921, tuvo mucha repercusión en ámbitos educativos, pero sus planteamientos no iban mucho más allá de ordenar los trabajos de Menéndez. Pelayo. De la misma época, 1920-1921, data la extensa y sugestiva Historia de la lengua y literatura castellana (comprendidos los autores hispano-americanos), de Julio Cejador y Frauca, cuyo subjetivismo desmedido echa por tierra en muchas ocasiones su vasta erudición. Ambas obras son claramente deudoras de la idea romántica del Volksgeist.

Más renovadoras fueron las Historias literarias de Alonso Cortés, Guillermo Díaz-Plaja y José Manucl Blecua. Estas iban dirigidas a un público de estudiantes de bachillerato, que se benefició no sólo de las síntesis que ofrecían estos reeditadísimos manuales, sino también, sobre todo en el caso de Guillermo Díaz-Plaja y José Manuel Blecua, de novedosos planteamientos en cuanto a la didáctica de la literatura y las humanidades. Sobre este último punto, también se podría traer a colación la Historia de la literatura española de Ángel Valbuena Prat (1937 y en sucesivas ampliaciones y reediciones del autor hasta 1968); sin embargo, sus mayores aciertos vienen de la mano de su valiente apuesta por la autonomía de la literatura y algunos madrugadores planteamientos comparatistas, así como su acierto al historiar a sus coetáncos. De Ángel Valbuena Prat, se pucde afirmar que es el historiógrafo literario más importante de su época y, seguramente, de la Historiografía literaria española en general.

Nos restaría, por último, hablar de las obras escritas por hispanistas extranjeros. Gerardo Diego cita las de Mérimée, Pfandl y la reciente Historia literaria de Diego Carlo Boselli y Cesco Vian (1941). No obstante, podrían añadirse otros nombres que, desde el inicio de la Historiografía literaria española, que, como se sabe, nació fuera de España, se han preocupado por historiar la literatura española: Bouterwerk, Sismondi, Ticknor, Fitzmaurice-Kelly, Hellmuth Petriconi, pero también Farinelli, Sarrailh, Bell... Las meritorias aportaciones de estos extranjeros fueron deudoras del planteamiento del Volksgeist español, que no sólo lo potenciaron en la Historiografía 


\section{LA HISTORIA DE LA HISTORIOGRAFÍA LITERARIA ESPAÑOLA}

literaria española, sino que, en buena medida, lo inventaron para el caso español al reparar sobre todo en las características más pintorescas de este ${ }^{8}$.

Pues bien, pertrechado de estas obras de consulta, Gerardo Diego recorre la Historia de la literatura española sin desviarse demasiado de esa idea del Volksgeist sobre la que hemos insistido. Las notas sobre los "Caracteres generales" de la literatura española [1946: 547], que añade como pórtico a su Historia literaria, giran, obviamente, en torno a esta idea. Estas características generales no son más que el apresurado inventario de las que Menéndez Pidal, Dámaso Alonso y tantos otros acuñaron (popularismo, realismo, idealismo...), y que representan, para las letras, el problema paralelo de la definición de la españolidad y sus características (catolicismo, imperialismo... $)^{9}$.

Pues bien, la caracterización del espíritu español y su literatura son explicados en la Historia literaria de Gerardo Diego en estos términos:

Mucho se ha discutido acerca de las notas distintivas del carácter español y su reflejo en la literatura. Sobre todo, el famoso realismo con su complacencia en lo tangible, en lo plástico, en lo característico, en lo feo, habría de ser, según la críticas positivista, un rasgo distintivo del genio de España, tan evidente en sus escritores, como en sus pintores o escultores, por ejemplo, de tallas religiosas. Desde hace años, se viene atenuando, gracias a una visión más matizada y exacta, este diagnóstico exclusivista del realismo español. Lo menos que se puede decir es que nuestros artistas y poetas, si geniales al dar corporeidad, alma y violencia expresiva a los datos de la realidad exterior, no se quedan sólo en eso, sino que saben igualmente evadirse hasta la más sublime creación abstracta o más enajenada fuga idealista [1946: 547]. ${ }^{10}$

Así, el Volksgeist repercute, sobre todo, en un tono hiperbólico, que nos deja comentarios como este que sigue sobre el Poema del Cid: «En suma, el Poema del Cid es no sólo venerable como obra fundadora de nuestras letras, sino digna, por sus altísimos valores poético, histórico, arqueológico y patrio, de ser considerada como una de las obras esenciales de nuestra literatura» [1946: 549]. En un principio, cabría afirmar que el Volksgeist es el criterio que timonea el canon; sin embargo, habría que objetar que, en ocasiones, da más bien la sensación de que no es tanto un criterio para seleccionar la calidad de las obras literarias, en cuanto una manera de argumentar esta calidad que la tradición crítica nos ha señalado. Comentarios hiperbólicos como el citado sobre

8.- Sobre el papel de los extranjeros en la Historiografía literaria española, vid. Romero Tobar [1999, 2003], y sobre estas Historias literarias descritas y otras de la época, los citados trabajos de Mainer [1981, 1994], Pozuelo Yvancos [2000], Núñez y Campos [2005]...

9.- La relación de características de la literatura española más representativa es la que preparó Menéndez Pidal [1951], a la que contestó Dámaso Alonso con su idea del dualismo de la literatura española [1978]. (En el apartado de referencias bibliográficas, puede verse la información sobre las diferentes ediciones de estos dos estudios tan relevantes, que datan originariamente de la primera década y segunda del XX respectivamente). Abad Nebot [1983: 27-90] ofrece un estado de la cuestión sobre este tema de la caracterización de la literatura española.

10.- Como podemos comprobar, Diego está glosando la idea de la caracterización de la literatura española dualista de Dámaso Alonso [1978], que no cita. Continúa el texto ilustrando esta idea con diferentes ejemplos de escritores y artistas: «Quizá el gusto por los extremos, el pasar de lo que se palpa lo que se sueña, de la picaresca a la mística, de la guerra ("polvo, sudor y hierro") a la contemplación extasiada, de Juan Ruiz o Góngora, sea lo que mejor nos define. A veces, como en el Greco o en Zurbarán, dentro de una misma obra, realismo e idealismo, tierra y cielo se superponen, y tenemos nuestro teatro o el Quijote. Los españoles hemos inventado la tragicomedia y la novela con su mezcla de realidad y fantasía. Y en la poesía hemos ampliado la escala, el teclado, por un lado hasta las jácaras desgarradas de Quevedo, por otro hasta los celestes esplendores de San Juan de la Cruz. Robusta fe religiosa, austeridad moral, gusto por la acción, persistencia de la materia poética tradicional a través de los siglos, popularismo compatible con las obras importantes, desdén o descuido por la publicación (ninguna literatura presenta tal cantidad de libros póstumos de poesía: Garcilaso, Fray Luis, San Juan, Góngora, Quevedo, Bécquer) son otros tantos caracteres que pueden señalarse» [1946: 547]. Acaso deberíamos considerar esta última idea sobre la poesía póstuma una observación original de Gerardo Diego. 


\section{ANTONIO MARTÍN EZPELETA}

el Poema del Cid, nos hacen pensar en cuánto hay de palabras de cara a la galería (de aceptación en la tribu, con fórmula de éxito en la crítica moderna) o de estilo engolado incorrectamente relacionado con el género de la Historia literaria.

En fin, en la misma línea del Volksgeist, debe entenderse el hecho de que Diego crea necesario ofrecer una descripción sobre "Lengua castellana" [1946: 547-548], de la que llega a afirmar rotundamente que es el dialecto «llamado a imponerse, por su superior sentido eufónico, la claridad y sencille $z$ de su sistema fonético, su audacia innovadora y la vocación militante y unificadora de la política castellana» [1946: 548]. Se puede afirmar que el que aparezcan estas notas sobre la lengua castellana relaciona la Historia literaria de Gerardo Diego con la tradición historiográfico-literaria decimonónica, cosa que sucede con otros muchos historiadores del XX (Cejador y Frauca, Giménez Caballero....).

Respecto a la división periodológica, excepto en un primer "Periodo primitivo" que llega hasta el XIV (el Cid, la lírica primitiva, el mester de clerecía, el Auto de los Reyes Magos...), divide simplemente por siglos, agrupando por géneros literarios las obras canónicas: en el XIV (el Libro de Buen Amor, Don Juan Manuel...); el siglo XV (Santillana, Mena y Manrique, los romances, Encina, La Celestina...); el siglo XVI (Boscán y Garcilaso, los místicos, Herrera, Ercilla...); el XVII (Cervantes, Góngora, Lope, Tirso, Calderón, Quevedo, Gracián...); el siglo XVIII (Meléndez. Valdés, Leandro Fernández de Moratín, Feijoo, Cadalso, Jovellanos...); cl XIX (Quintana, Espronceda, Zorrilla, Larra, Bécquer, Galdós, Valera...) ${ }^{11}$; y cl XX (Rubén Darío, Juan Ramón Jiménez, García Lorca, Benavente, Valle-Inclán, Unamuno, Baroja, Miró, Ortega, D'Ors... $)^{12}$. Como se comprenderá, en las pocas páginas de la Historia literaria de Gerardo Diego apenas se ofrecen unas pocas notas descriptivas de los diferentes autores y obras. Pero, aunque no es la norma, como decimos, en ocasiones, eso sí, se incluyen fragmentos que superan la descripción insulsa de la fecha de publicación de las obras. Es el caso, por ejemplo, de este fragmento sobre La Celestina:

Pasma la potencia psicológica de Rojas para crear caracteres -Celestina, Melibea, Calixto, las mozas y rufianes- de tanta riqueza de matices y de un vigor de dibujo sin desmayo, el arte complejo y gradual

11.- Advierte al principio del epígrafe sobre el XIX: «El nuevo siglo difícilmente puede ser estudiado en una sola pieza. Es costumbre dividirlo en tres secciones. Los treinta primeros años son de prerromanticismo o, si se quiere, de un neoclasicismo más animado y colorido que el del siglo anterior, al cual, en el fondo, sigue fiel. Viene luego la generación romántica, que se consume pronto en su propia fiebre. De tal modo, que a mediados de siglo ya se inicia la reacción llamada realista, que se impondrá hacia 1870. Poco antes de concluir, una nueva estética, favorecida por el ejemplo de los poetas hispanoamericanos prepara la mutación del fin de siglo: el movimiento crítico y estético del "98" y del "modernismo"» [1946: 595]. En el resto del apartado sobre el siglo XIX, los autores se ordenan según esta división, aunque no se profundiza apenas en las características definitorias de estas tres líneas generales.

12.- Introduce esta época la siguiente valoración: «Nos falta perspectiva para contemplar un siglo que aún no ha cumplido la mitad de su curso. Por ello, nuestra impresión habrá de ser, por fuerza, provisional e incompleta, tanto más insegura y rápida cuanto nos acerquemos a nuestros días. De los escritores que en este siglo realizan toda o la mayor parte de su obra, unos han fallecido tras de una labor completa, de toda una vida de suficiente longitud para dar la medida de sus posibilidades. Otros han desaparecido en edad apenas madura o en plena juventud. De unos y de otros podemos ocuparnos. De entre los vivientes, lo haremos igualmente de aquellos que por haber traspuesto la cumbre vital, of recen ya su perfil bastante realizado, aunque podamos esperar aún obras importantes y aun sorpresas. En conjunto, se nos aparece la literatura contemporánea como una digna continuación -e incluso superación en el sector poético- del brillante resurgir de fines de siglo, que se anunciaba como un posible siglo nuevo de oro. Pueden distinguirse ya dos generaciones: la del "98" ó "900" y la que se define hacia 1927 ó 30, ya que treinta años son los que hay que contar para el desarrollo de una generación, aunque la prisa moderna lleve a los impacientes a hablar de generaciones cada década o lustro, casi cada "quinta". Pero en ese sentido, convendría emplear otra palabra” [1946: 6111. En realidad, sólo se refiere mínimamente como generaciones literarias al 98 y Modernismo. Además, del canon de nueve poetas que suelen ubicarse en la llamada generación del 27, sólo aparece García Lorca. 


\section{LA HISTORIA DE LA HISTORIOGRAFÍA LITERARIA ESPAÑOLA}

con que se va llevando la acción, y, sobre todo, la embriagadora puesía de la noche amorosa. El huerto de Melibea se anticipa al balcón de Verona, y sus efluvios son aún más intensos y exquisitos. Shakespeare, por otra parte, como tantos otros poetas de su siglo, debe mucho a Rojas. Los 21 actos están escritos en una prosa que es prodigio alterno de realismo y de identidad, una equivalencia del último gótico y del plateresco arquitectónicos [1946: 558].

En fin, las pocas páginas de la Historia literaria de Gerardo Diego no impiden que se seleccione un canon de autores. Aunque, como se habrá comprobado, no hay muchas desviaciones del canon canónico. Se observa, por lo demás, que el género mejor atendido es la poesía. Así, por cjemplo, Clarín y su obra son descritos en tres líneas, mientras que Basterra o Manuel Machado ocupan párrafos bastante más extensos. Muchas veces, además, el discurso se afecta:

En cuanto a Garcilaso, es el poeta sin tacha, el poeta lírico puro de España. Él encuentra el tono, el timbre más armonioso, terso y delicado del endecasílabo y, en general, de la lírica castellana. Todo en él se aristocratiza sin afectación ninguna, usando las palabras más modestas en su sitio justo, donde más eficazmente resplandecen. Garcilaso es la piedra de toque de la poesía española. Sienta autoridad y su sereno esplendor no conocerá eclipses. Penetrado de reminiscencias latinas o italianas, es, sin embargo, de una absoluta originalidad de acento y sentimiento. El amor tiernamente apasionado, la sensación física de la belleza natural, el matiz difícil de los afectos de amistad, rendimiento o consuelo, se reflejan en su poesía con luminosa reverberación. Sus tres églogas, sus sonetos, sus elegías, canciones y epístolas quedarán para siempre en los oídos de los poetas españoles del porvenir como dechados de gracia y de elegancia [1946: 562].

Lope de Vega es uno de los autores a los que dedica mayor atención, a pesar de que afirme Diego: «Debemos abandonar a Lope dejándonos casi todo por decir» [1946: 583]. El tono, como ya hemos ilustrado, se afecta en este caso también:

La vida de L.ope de Vega, menos bella, moralmente hablando, que la de Cervantes, presenta un atractivo novelesco y psíquico de primer orden. A juzgar por sus hechos y sus palabras, Lope fue un insaciable, un ambicioso, un hiperestésico, un sensual exigente e imaginativo, un verdadero "monstruo de la Naturaleza" por su furiosa y proteica actividad mundana y mental, capaz de embarcarse en la Armada contra Inglaterra o de abofetear a una querida, de "amar y aborrecer" (los dos extremos en que él mismo reconoce que únicamente sabe vivir), de enternecerse ante el balbuceo de un niño, ante la gracia mojada de una florecilla, o de arrancarse sangre de los lomos con las disciplinas del penitente. Sólo teniendo en cuenta su inverosímil fuerza biológica, su poder de fecundidad, que no reconoce par en la literatura universal, pues que nunca se dio aliado como en él con la más constante y finísima calidad, podemos acercarnos a la selva inmensa de su obra con posibilidades de comprensión y valoración. Un estudio mínimo de ella requeriría ocuparse sucesivamente del poeta lírico y épico, del dramaturgo, del prosista, sin olvidar su teoría del mundo y del arte [1964: 581].

Como afirmábamos más arriba, el género de la poesía es el mejor estudiado. Interesan sus comentarios sobre la poesía de Góngora, tomado como referente poético de Diego y la Generación del 27, que, entre otros punto de su autodefinición (donde Diego y sus antologías tuvieron tanta importancia) ${ }^{13}$, se encontraba la revalorización del poeta cordobés, como el archiconocido episodio en el Atenco de Sevilla escenificó:

El genio poético de Góngora, su felicidad para la imagen fulgurante y muchas veces elíptica y misteriosa, quedaba indemne. Su sentido aristocrático le alejaba a los antípodas del lenguaje utilitario y prosaico. La poesía absoluta, la poesía pura, la poesía creada que decimos hoy, estaba esencialmente adivinada y perfectamente realizada dentro de las limitaciones humanísticas. Mucho tiempo ha tardado la crítica en darse cuenta de la hazaña gongorina. Sólo en nuestro siglo se ha rendido a Góngora la justicia y la gloria que le corresponde. No busquemos en su poesía sublimidades espirituales, intenso calor humano. Su reino no es ese. Pero en su reino es único [1946: 578].

13.- Vid. al respecto la importante monografía de $A$ nderson El veintisiete en tela de juicio. Examen de la historiografía generacional y replanteamiento de la vanguardia histórica española [2005]. 


\section{ANTONIO MARTÍN EZPELETA}

La otra figura influyente del XX es Rubén Darío, un nicaragüense que, como suele ocurrir, tiene cabida en la Historia de la literatura española:

El gran cantor nicaragüense pertenece a la literatura americana. Pero aunque se le estudie en otra parte, también por derecho propio hay que incluirle en la española, que, sin esa pieza capital que es su poesía, perdería su hilo biológico. Darío trae a nuestra poesía una novedad esencial. «Peregrinó mi corazón y trajo de la sagrada selva la armonía». La sagrada selva es el mundo clásico, mitológico pagano, y es también la selva americana, la sangre del indio ancestral. De América y de París proceden las dos fuentes principales de la renovación poética de Rubén. Sus libros modernistas, Azul... y Prosas profanas, despliegan toda la deslumbrante gama de sus sonoridades inéditas y de sus colores fastuosos, delicados, violentos o exquisitos. Se comprende hoy la polvareda de escándalo que armó la presencia de poesía tan descastada, tan neológica, tan impertinente en una España estéticamente letárgica, a pesar de los esfuerzos de nuestros precursores [...] [1946: 612].

De manera sucinta - y aséptica- se refiere un poco más adelante a otros poetas del XX, como Miguel Hernández, que lo aborda al citar los escritores ya muertos en el XX (Basterra, Bacarisse, Juan Panero... [1946: 614]). Con García Lorca, sin embargo, hace una excepción, pues García Lorca es el único de los poetas famosos del 27 sobre el que Diego se permite explayarse:

Pero ninguna pérdida tan dolorosa e incalculable como la de Fídirico García LoRCA (1898-1936). En la $v o z$ de timbre tan fresco y oscuro del gran poeta granadino, la milenaria tradición del pueblo español encuentra de modo pleno su mejor sabor y gracia, como en la de un nuevo Lope de Vega.

Fue maravilla que una poesía y un poeta que parecían nacidos para el goce de una minoría de refinados conquistasen tan rápidamente la devoción de enormes círculos de lectores y espectadores. Sin duda, el éxito de su teatro y la irradiación de una simpatía personal y de una sensibilidad milagrosa de juglar, poeta, mimo, dibujante y músico en una pieza contribuyeron eficazmente [... [ [1946: 615].

No aporta demasiado, pues, sobre su propia generación literaria, siendo, además, como hemos dicho, Diego uno de sus principales promotores. A Ángel Valbuena Prat es a quien debemos la primera y bastante certera definición de esta generación literaria en una Historia literaria.

Por otro lado, es interesante observar que, a pesar de las restricciones que impone la extensión de su trabajo, Diego no deja de dedicar un par de páginas a la «Crítica e historia literaria» [1946: 610-611]. Explica la línea filológica que arranca en Amador de los Ríos para detenerse en Menéndez. Pelayo. Sobre la obra del santanderino, concluye:

El defecto principal de su obra está en ese exceso digresivo, en la incapacidad para obedecerse a sí mismo en el plan trazado. Para guiarse en el océano de sus obras hace falta una carta de marear, que todavía, por desgracia, no ha sido trazada. Errores de detalle, alguna que otra injusticia o ligereza son poca cosa para desacreditar a un hombre de ciencia, a un poeta tan generalmente inspirado y certero como D. Marcelino. La fecundidad de su obra, viva está hoy todavía en la de sus discípulos directos o de segunda generación. Los métodos se han afinado, la investigación es hoy más escrupulosa, la precisión filológica, mayor, pero el fuego creador no ha vuelto a arder con tanta esplendorosa potencia [1946: 611].

Por último, cierran la obra, como hemos indicado, Ortega y D'Ors, dentro de un capítulo dedicado a los «Críticos, historiadores y ensayistas» [1946: 620-621]. Reproduzcamos lo que escribe sobre el autor de España invertebrada:

Cerraremos estos apuntes con dos escritores ensayistas que han ejercido y ejercen una honda intluencia en la filosofía y estética de la juventud. José Ortega y Gasset (n. 1883), nuestro primer metafísico, ha expuesto su filosofía en libros de ensayos de tan seductora y plástica belleza literaria que ha perjudicado su crédito entre lectores apresurados que no advertían la firmeza de su sistema latente. Su sagacidad de Espectador universal sabe encontrar en el panorama inagotable de la vida el secreto profundo que la apariencia esconde. Su estilo es soberbio, vigoroso, cálido y brillante y ha impresionado a muchos jóvenes escritores, que le deben su formación no sólo mental, sino estética y estilística. [1946: 621] 


\section{LA HISTORIA DE LA HISTORIOGRAFÍA LITERARIA ESPAÑOLA}

En fin, como se habrá comprobado tras el repaso general que hemos llevado a cabo, esta de Gerardo Diego es una Historia literaria española constreñida por el formato donde se incluye, una Historia de la literatura universal escolar, a juzgar por las citadas palabras del prólogo. No es, pues, el cjemplo de Historia literaria que podría haber escrito Gerardo Diego; sino una suerte de catálogo de autores y obras canónicas mínimamente descritas. Realmente, no hay apenas contenido crítico novedoso. Se trata de una repetición de la tradición historiográfico-literaria fundamentada en el genio español. Incluso se adivina tras clla un mero cjercicio de síntesis de otras Historias literarias, sin mayor aportación, ni siquiera testimonial. Acaso algunos comentarios indirectos y la prosa desinhibida con que está escrita sean los mayores méritos de esta Historia literaria que, por lo demás, satisfaría perfectamente el fin divulgativo con que fue escrita.

****

La Historia de la crítica literaria desempeña dos importantes funciones dentro del mundo del estudio literario. De un lado, ofrece un panorama de la labor de los estudiosos del pasado, que comporta, a su vez, una recuperación de sus logros más relevantes, muchos de ellos definitivos. De otro, satisface esa saludable tarea que comparten todas las ramas científicas: la continua revisión de sus propios objetivos, planteamientos y metodologías.

En el pujante mundo del hispanismo, esta revisión de la crítica literaria, a pesar de haber incrementado su interés en los últimos tiempos (especialmente se ha atendido al papel de críticos de muchos escritores: Galdós, Salinas, Díez-Canedo..., o de determinadas instituciones, como el Centro de Estudios Históricos, por no hablar de los estudios sistemáticos de revistas o suplementos literarios como Los Lunes del Imparcial), todavía presenta lagunas importantes. Una de las más relevantes es la carencia de una Historia de la historiografía literaria española que dé cuenta de la historia de las Historias literarias españolas.

Como hemos insistido en este trabajo, la disciplina de la Historiografía literaria persigue el análisis de la conformación del canon y la explicación de este a partir de cuestiones principalmente socio-históricas, así como su plasmación en Historias literarias y antologías que, por su parte, responden también a un particular momento de la Historia de la filología. Pero su interés va más allá del plano historicista, puesto que, como los teóricos de la literatura del momento han observado, las Historias literarias constituyen un lugar privilegiado para la reflexión sobre la idea de la Historia de la literatura nacional y de la literatura, en definitiva. Por todas estas razones, se antoja necesario intensificar los estudios historiográfico-literarios para caminar hacia esa propedéutica Historia de la historiografía literaria española largamente aplazada. Es hora, pues, de poner manos a la obra.

\section{REFERENCIAS BIBLIOGRÁFICAS}

Abad Nebot, Francisco, Caracterización de la literatura española y otros estudios, Madrid, U.N.E.D., 1983 .

Alonso, Dámaso, "Escila y Caribdis de la literatura española", Obras completas. Góngora y el gongorismo, vol. 5, Madrid, Gredos, 1978, pp. 243-258. [Originariamente fue el discurso que pronunció Dámaso Alonso en el Ateneo de Sevilla en la conmemoración del centenario de la muerte de Góngora en 1927; 1." ed., Cruz y Raya, n. 7 , 15 de octubre de 1933, pp. 77-102].

Álvarez Barrifntos, Joaquín, y Antonio Mrstre, "Orígenes de la historia de la literatura española", Víctor García de la Concha (dir.), Guillermo Carnero (coord.), Historia de la literatura española. Siglo XVIII, vol. 6, Madrid, Espasa-Calpe, 1995, pp. 108-136.

Anderson, Andrew. A., El veintisiete en tela de juicio. Examen de la historiografía generacional y replanteamiento de la vanguardia histórica española, Madrid, Gredos, 2005. 


\section{ANTONIO MARTÍN EZPELETA}

Aullón de: Haro, Pedro, El ensayo en los siglos XIX y XX, Madrid, Playor, 1984.

_- Los géneros ensayísticos en el siglo XX, Madrid, Taurus, 1987.

BAASNER, Frank, Literaturgeschichtsschreibung in Spanien von den Anfägen bis 1868, Frankfurt am Main, Vittorio Klostermann, 1995.

Bretrán Almiría, Luis, y José Antonio Escrig (eds.), Teorías de la historia literaria, introducción, compilación de textos y bibliografía de Luis Beltrán Almería y José Antonio Escrig, Madrid, Arco/Libros, 2004.

— , «Leyendo en las historias géneros y estilos», en Lconardo Romero Tobar (ed.), Historia literaria/Historia de la literatura, Zaragoza, Prensas Universitarias, 2004, pp. 31-43.

Bloom, Harold, et al., El canon literario, introd. y compilación de textos de Enric Sullà, Madrid, Lecturas, 1998.

Carballo Picazo, Alfredo, "El saber literario", en Guillermo Díaz-Plaja (dir), Historia General de las Literaturas Hispánicas. Literatura contemporánea, introd. de Ramón Menéndez. Pidal, Barcelona, Vergara, 1967, vol. 6, pp. 339-373.

Cébrán, José, "Historia literaria", en Francisco Aguilar Piñal (ed.), Historia literaria de España en el siglo XVIII, Madrid, C.S.I.C. / Trotta, pp. 513-592.

Ceserani, Remo, Introducción a los estudios literarios, trad. de Jorge Ledo Martínez y apéndice bibliográfico de David Roas, Barcelona, Crítica, 2004.

Diego, Gerardo, Menéndez Pelayo en la Historia literaria, Santander, Ayuntamiento de Castro Urdiales / Biblioteca Antonio Hurtado de Mendoza, 1956.

Fetrnández-Cifuentes, Luis, "La literatura española en los Estados Unidos: historia de sus historias", en Leonardo Romero Tobar (ed.), Historia literaria/Historia de la literatura, Zaragoza, Prensas Universitarias, 2004, pp. 253-272.

Garrido Palazón, Manuel, "La Evolución de la Historiografía Literaria Románica”, en Pedro Aullón de Haro (ed.), Teoría/Crítica, n. ${ }^{\circ} 1$, monográfico "Teoría de la Historia de la literatura y el arte", Madrid, Verbum, 1994, pp. 85-119.

Gunl.tén, Claudio, Literature as System: Essays toward the Theory of Literary History, Princeton, Princeton University Press, 1971.

__, Teorías de la historia literaria. (Ensayos de teoría), Madrid, Espasa-Calpe, 1989.

Hutchion, Linda, y Mario J. Valdés San Martín (eds.), Rethinking Literary History. A Dialogue on Theory, Nueva York, Oxford University Press, 2002.

Laín Entral.go, Pedro, Menéndez Pelayo. Historia de sus problemas intelectuales, Madrid, Editora Nacional, 1944.

MAINER, José-Carlos, "De historiografía literaria española: el fundamento liberal", en VV. AA., Estudios sobre Historia de España. Homenaje a Tuñón de Lara, Santander, U.I.M.P., vol. 2, 1981, pp. 439-479.

__ "La invención de la literatura española", en José M." Enguita y José-Carlos Mainer (eds.), Literaturas regionales en España, Zaragoza, Instituto "Fernando el Católico", 1994, pp. 2345.

- "Sobre el canon de la literatura española del siglo XX", en Harold Bloom et al., El canon literario, introd. y compilación de textos de Enric Sullà, Madrid, Lecturas, 1998, pp. 271299. 


\section{LA HISTORIA DE LA HISTORIOGRAFÍA LITERARIA ESPAÑOLA}

Martín Ezpeleta, Antonio, "La Historiografía literaria española de la primera mitad del siglo $\mathrm{XX}$ ", en <www.liceus.com> [Historia literaria española dirigida por Antonio Alvar Ezquerra y Julia Barella].

—, "La Historiografía literaria española hoy. Notas sobre los manuales de literatura de Giménez Caballero", en VV. AA., I Congreso Internacional de Filología Hispánica: Jóvenes investigadores. "Orientaciones metodológicas" (Oviedo, 8-11 de mayo de 2006), Oviedo, Universidad de Oviedo, en prensa.

Menéndez. Pidal, Ramón, "Caracteres primordiales de la literatura española con referencias a las otras literaturas hispánicas, latina, portuguesa y catalana”, en Los españoles en la historia y en la literatura. Dos ensayos, Buenos Aires, Espasa-Calpe, 1951, pp. 159-229 [1." ed., Guillermo Díaz-Plaja (dir.), Historia general de las literaturas hispánicas, Barcelona, Vergara, 1949, vol. 1, pp. XIII-LıX; estas características de la literatura española habían sido publicadas seminalmente en la Revue internationale de l'Enseignement (15 de noviembre de 1916) y en el número 20 del Bulletin Hispanique (1918)].

Meregal..., Franco, "Panorama de las historias de la literatura española", en José Francisco Alcina et al. (eds.), Historia de la literatura española, Madrid, Cátedra, 1990b, vol. 1, pp. 25-34.

NúÑez, Gabriel, y Mar Campos Fernánidiz-Fígares, Cómo nos enseñaron a leer: Manuales de literatura en España, 1850-1960, estudio preliminar de Juan Carlos Rodríguez, Toledo, Akal, 2005 .

Palau y Dulcet, Antonio, Manual del librero hispanoamericano. Bibliografía general española e hispanoamericana desde la invención de la imprenta hasta nuestros tiempos con el valor comercial de los impresos, Barcelona, Librería Palau, 1948-1977², 28 vols.

Portolés, José, Medio siglo de Filología española (1896-1952). Positivismo e idealismo, Madrid, Cátedra, 1986.

Pozufilo Yvancos, José María, El canon en la teoría literaria contemporánea, Valencia, Episteme, $1996^{2}$.

(coord.), Ínsula, n. ${ }^{\circ}$ 600, diciembre de 1996. [Monográfico titulado "Un viaje de ida y vuelta: el canon"].

—_, "Ángel Valbuena: La renovación de la Historiografía literaria española”, Monteagudo, monográfico "Ángel Valbuena Prat y la Historiografía literaria española", José María Pozuelo Yvancos (coord.), 3." época, n. ${ }^{\circ}$ 5, 2000, pp. 51-69.

y Rosa María Aradra SÁnchez, Teoría del canon y literatura española, Madrid, Cátedra, 2000.

Prades, Juana de José, La Teoría Literaria (Retóricas, Poéticas, Preceptivas, etc.), Madrid, Instituto de Estudios Madrileños, 1954.

Ródenas de Moya, Domingo, "Introducción”, Benjamín Jarnés, Obra crítica, introd., ed. y notas de Domingo Ródenas de Moya, Zaragoza, Institución "Fernando el Católico", 2001, pp. 9-35

Román, A, "Antología e historias de la literatura publicadas en los Estados Unidos", Cuadernos bibliográficos, n. ${ }^{\circ} 32,1975$, pp. 5-27.

Romero TObar, Leonardo, "Las historias de la Literatura y la fabricación del canon", en Jaume Pont y Josep M. Sala-Valldaura (eds.), Cànon literari: ordre $i$ subversió, Lleida, Institut d'Estudis Ilerdencs, 1998, pp. 47-64.

— , "Entre 1898 y 1998: la Historiografía de la literatura española", RILCE, vol. 15, n. ${ }^{\circ} 1,1999$, pp. $27-49$. 


\section{ANTONIO MARTÍN EZPELETA}

_- "Las historias literarias de los hispanistas escritores", Boletín de la Fundación Federico García Lorca (B.F.G.L.), n. ${ }^{\circ} 33-34,2003$, pp. 197-208.

(ed.), Historia literaria/Historia de la literatura, Zaragoza, Prensas Universitarias, 2004.

Rubio Jiménez, Jesús, "Primeras historias y antologías teatrales de la posguerra", en Leonardo Romero Tobar (ed.), Historia literaria/Historia de la literatura, Zaragoza, Prensas Universitarias, 2004, pp. 393-419.

Sr:Ris, Homero, Manual de bibliografía de la literatura española, Nueva York, Syracuse University, Centro de Estudios Hispánicos, 1948.

Simón Di̊z, José, Bibliografía de la literatura hispánica, pról. de J. de Entrambasaguas, 3." ed. corregida y aumentada, Madrid, C.S.I.C., 1983, vol. 1.

UrZAINQUI, Inmaculada, "El concepto de historia literaria en el siglo XVIII", en VV. AA., Homenaje a Álvaro Galmés de Fuentes, Oviedo / Madrid, Universidad de Oviedo / Gredos, 1987 , vol. 3, pp. 565-589.

VAL.s.S, Fernando, La enseñanza de la literatura en el franquismo (1936-1951), pról. de JoséCarlos Mainer, Barcelona, Antoni Bosch, 1983.

White, Hayden, El contenido de la forma. Narrativa, discurso y representación histórica, trad. de Jorge Vigil Rubio, Barcelona, Paidós, 1992 [1." ed., The Content of the Form. Narrative Discourse and Historical Representation, Baltimore, The Johns Hopkins University Press, 19871 . 